\title{
Regulatory Differences in the Stress Response of Hippocampal Neurons and Glial Cells after Heat Shock
}

\author{
Charles J. Marcuccilli, ${ }^{1}$ Sameer K. Mathur, ${ }^{2}$ Richard I. Morimoto, ${ }^{2}$ and Richard J. Miller ${ }^{1}$ \\ ${ }^{1}$ Department of Pharmacological and Physiological Sciences, The University of Chicago, Chicago, Illinois 60637, and \\ 2Department of Biochemistry, Molecular Biology, and Cell Biology, Northwestern University, Evanston, Illinois 60208-3500
}

\begin{abstract}
During periods of stress, cells depend on a transient, highly conserved, and regulated response to maintain homeostasis. This "heat shock response" is mediated transcriptionally by a multigene family of heat shock factors (HSF). The presence of multiple HSF suggests that activation of a given HSF is stressspecific. Using Western blot analysis, we have demonstrated the inability of primary cultured rat hippocampal neurons to induce a heat shock response after hyperthermia. In contrast, secondary cultured rat glial cells demonstrated a robust response. Examination of whole-cell extracts from the two cell types with gel shift mobility analysis and Western blot analysis revealed that although glial cells express HSF1 and HSF2, hippocampal neurons only express HSF2. Incubation of whole-
\end{abstract}

cell extracts with monoclonal antisera raised against HSF1 and HSF2 before gel shift mobility analysis demonstrated HSF1 DNA-binding activity in glial cells and HSF2 DNA-binding activity in neurons. HSF1 has been shown to be the principal mediator of heat-induced heat shock gene expression. These results suggest that the deficient heat shock response of hippocampal neurons at this developmental stage is attributable to a lack of HSF1 expression. Furthermore, these results suggest that considerations of selective neuronal vulnerability to environmental stress should include the principal mediators of the stress response, the HSF.

Key words: heat shock; HSP70; hippocampus; HSF; selective vulnerability; glia
It has been shown previously that neurons of the hippocampal formation are selectively vulnerable to certain stresses. Attempts to resolve the molecular basis for this vulnerability have focused on excitatory amino acid receptors (Mattson et al., 1991a), intracellular $\mathrm{Ca}^{2+}$ buffering (Mattson et al., 1991b), antioxidant activity (Akai et al., 1990; Liu et al., 1993), and the stress response (Kato et al., 1993). When most cells undergo potentially harmful stress, they respond by synthesizing a set of highly conserved proteins, classically termed heat shock proteins (HSP). Once synthesized, these proteins have the ability to protect the cell from future stresses ("cross-tolerance") (Lindquist and Craig, 1988; Li et al., 1992; Sanchez et al., 1992). Induction of these HSP after stress is mediated by a multigene family of heat shock transcription factors (HSF). These factors bind to upstrean response elements, the heat shock elements (HSE), located in the promoters of inducible heat shock genes as well as some other genes (Morimoto et al., 1992; Lis and Wu, 1993; Morimoto, 1993). The recent discovery of multiple HSF genes in tomato (Scharf et al., 1990), chicken (Nakai and Morimoto, 1993), mouse (Sarge et al., 1991), and human (Rabindran et al., 1991; Schuetz et al., 1991) has raised interesting questions regarding the reasons for this diversity. One possibility is that each HSF is concerned with

Received Aug. 8, 1995; revised Oct. 16, 1995; accepted Oct. 18, 1995.

C.J.M and R.J.M. were supported by Public Health Service Grants DA-02121, DA-02575, and MH-40165. C.J.M. was supported additionally by MD/PhD Training Program Grant HD07009 and Pharmacology Training Grant 5T32GM07151-20. S.K.M. and R.I.M. were supported by Public Health Service Grant GM38109 and a grant from the March of Dimes. S.K.M. was supported additionally by Medical Scientist Training Program Grant 5T32GM08152. We thank Sue Fox for help in preparing the figures. We also thank Susan Lindquist for the generous gift of the anti-HSP90 antibody, Brian C. Freeman for the rHSF1, Arthur A. Simen for help with statistical analysis, and Jose J. Cotto for anti-HSF1 and anti-HSF2.

Correspondence should be addressed to Richard J. Miller, Department of Pharmacological and Physiological Sciences, The University of Chicago, 947 E. 58th Street, Chicago, IL 60637.

Copyright $\bigcirc 1996$ Society for Neuroscience $\quad 0270-6474 / 96 / 160478-08 \$ 05.00 / 0$ orchestrating the cellular response to different types of stress or other phenomena such as development (Sistonen et al., 1992, 1994; Sarge et al., 1994).

Studies of the regulation of the heat shock response in the CNS have resulted in several intriguing observations (for review, see Marcuccilli and Miller, 1994). For example, although HSP induction in hippocampal pyramidal neurons has been observed consistently after transient ischemia in vivo (Vass et al., 1988; Kato et al., 1993), it is unclear whether this type of neuron demonstrates a heat shock response after hyperthermia. Thus, although Sprang and Brown (1987) and McCabe and Simon (1993) did not observe HSP70 induction after heat shock, Pardue et al. (1992) have demonstrated hsp $70 \mathrm{mRNA}$ induction in both adult and aged rats after a $42^{\circ} \mathrm{C}$ heat shock. However, in this case glia of the corpus callosum or CA4 region of the hippocampus demonstrated a 17 to 20 -fold higher level of hsp 70 induction than did neurons of Ammon's horn (Pardue et al., 1992). Two other studies have shown that, in contrast to the hippocampal pyramidal neurons, glial cells demonstrate a vigorous response to heat (Sprang and Brown, 1987; McCabe and Simon, 1993). These studies suggest that, at the very least, hippocampal pyramidal neurons have a limited ability to respond to heat shock compared with their glial counterparts. The induction of stress proteins in glial cells also has been demonstrated in vitro (Nishimura et al., 1988). The differences in HSP70 induction between certain neuronal cell types and glial cells may be attributable to a defect in the ability of neuronal cells to activate HSF. To test this possibility, we compared HSF activation in primary cultured hippocampal neurons and secondary cultured glial cells.

\section{MATERIALS AND METHODS}

Cell culture method. Hippocampal neuron cultures were prepared according to the Banker culture method as described previously (Abele et al., 1990). Briefly, hippocampi from $17 \mathrm{~d}$ embryonic Holtzman rats were 
removed and trypsin-dissociated. Neurons were plated on either $15 \mathrm{~mm}$ round-glass coverslips (for staining) or $35 \mathrm{~mm}$ Falcon tissue culture dishes (for biochemistry; Becton Dickinson, Lincoln Park, NJ). To condition the scrum-frec defincd medium [N2 supplements (Bottenstein and Sato, 1979) as modified by Bartlett and Banker (1984)], $32 \mathrm{~mm}$ perforated plastic coverslips containing a feeder layer of glial cells (see below) were placed in the culture dishes such that the glial cells directly opposed the neurons. Glass coverslips containing neurons for staining were placed over a feeder layer of glial cells grown in $60 \mathrm{~mm}$ tissue culture dishes. Maternal rats were housed and anesthetized irreversibly in accordance with institutional guidelines. This culture method, consisting of $3.6 \pm$ $1.7 \%$ glia, enables us to heat shock reasonably pure neurons in the absence of glial cells. Glial cell percentage was determined immunocytochemically by probing for glial fibrillary acidic protein (GFAP). The monoclonal antibody to GFAP was obtained from Boehringer Mannheim (Indianapolis, IN). Hippocampal neuron cultures were heat-shocked when the cells were at least $10 \mathrm{~d}$ in vitro.

Glial cells were prepared as described by Booher and Sensenbrenner (1972). Postnatal (3-5 d) Holtzman rat pups were used to obtain cortical glial cells. Briefly, cortices of rat pups were trypsin-dissociated and plated in DMEM (Gibco, Grand Island, NY) supplemented with $10 \%$ tetal calf serum (FCS; Gibco) in $60 \mathrm{~mm}$ tissue culture dishes. After $24 \mathrm{hr}$, the $10 \%$ FCS-DMEM was replaced with $10 \%$ horse serum-DMEM (Gibco). Secondary cultures were performed by trypsin dissociation when the cells were $4 \mathrm{~d}$ in vitro. Glial cells were replated on $\sim 32 \mathrm{~mm}$ perforated plastic coverslips to serve as a feeder layer for neurons or in $60 \mathrm{~mm}$ Falcon tissue culture dishes to be used in biochemical experiments. Glial cells then were grown in N2.1-supplemented DMEM for at least $3 \mathrm{~d}$ before heat shock. Glial cclls were at least $14 \mathrm{~d}$ in vitro at the time of heat shock. Neurons and glial cells in Figure 1 were stained with fluorescein diacetate according to Favaron et al. (1988).

Heat shock. Hippocampal neurons grown on $35 \mathrm{~mm}$ tissue culture dishes and glial cells grown on $60 \mathrm{~mm}$ culture dishes were heat-shocked in a closed, constant temperature water bath. Before heat shock, plastic coverslips containing the feeder layer of glial cells were removed from the neurons, placed in $100 \mathrm{~mm}$ Petri dishes containing N2.1-supplemented DMEM, and stored at $37^{\circ} \mathrm{C}$ in a humidified, $\mathrm{CO}_{2}$-regulated incubator for the duration of the heat shock. The N2.1 growth medium of the neurons was collected and saved. Heat shocks were carried out in $25 \mathrm{~mm}$ 4-(2-hydroxyethyl)-1-piperazineethanesulfonic acid-buffered N2.1-supplemented DMEM conditioned by glial cells for 2-3 d. After heat shock, the original growth media and feeder layer of glial cells (for neuronal cultures) were replaced. The cells were allowed to recover in a $37^{\circ} \mathrm{C}$ humidified, $\mathrm{CO}_{2}$-regulated incubalor where indicated. Control cells were maintained at $37^{\circ} \mathrm{C}$ for $60 \mathrm{~min}$ in a humidified, non- $\mathrm{CO}_{2}$-regulated incubator followed by a $12 \mathrm{hr}$ recovery as described above.

Westem immunoblot analysis. The primary antibodies included a monoclonal antibody specific for the inducible form of HSP70 (anti-HSP70) diluted 1:1000 (StressGen Biotechnologies, Victoria, BC, Canada), a polyclonal antibody raised against HSP90 (anti-HSP90) diluted 1:200 (generously provided by Susan Lindquist, The University of Chicago, Chicago, IL), polyclonal sera raised against HSF1 and HSF2 (Sarge et al., 1993), and the $3 a 3$ monoclonal antibody, diluted 1:10,000, which recognizes IISP70 and p72/IISC70 "IISC" denotes the constitutive form of this family) (Amici et al., 1992). The appropriate secondary antibody, horseradish peroxidase-conjugated goat anti-mouse or anti-rabbit immunoglobulin G (Promega, Madison, WI), was used at a dilution of 1:20,000. Western immunoblot analysis was performed as described previously (Sarge et al., 1993), except that the StressGen HSP70-specific monoclonal antibody was diluted in PBS containing 5\% nonfat dry milk. Detection of the signal was performed with the electrogenerated chemiluminescence (ECL) Western Blot Detection Kit (Amersham, Arlington Heights, IL).

For Western immunoblot analysis of HSC70, ECL detection was performed with the exception that blots were exposed to preflashed XAR film (Eastman Kodak, Rochester, NY). After detection, HSC70 bands were quantitated with scanning densitometry. A standard curve was prepared with area values determined by densitometry as the independent variable and the anount of extract as the dependent variable. The curve was fitted by least-squares using the SAS program (SAS Institute, Cary, NC). HSC70 content for neuronal preparations was expressed as glial-equivalents determined by extrapolation of the standard curve. 'The percent of HSC70 in neurons compared with glia was determined by dividing glial-equivalents ( $\mu$ g of protein) by total neuronal protein ( $\mu \mathrm{g}$ of total protein) and then multiplying by 100 .

Native gel shift analysis. After heat shock, whole-cell extracts were prepared as described previously (Mosser et al, 1988). Crel mobility shift analysis was performed as described previously with the exception that $\mathrm{NaCl}$ was not added to the binding buffer (Mosser et al., 1990). HSF DNA-binding activity was analyzed using the self-complimentary idealized HSE oligonucleotide probe $\left(5^{\prime}\right.$ CTAGAAGCTTCTAGAAGCTTCTAG-3') containing four perfect-inverted NGAAN repeats. Gel mobility shift analysis with the oligonucleotide probe containing a cAMP response element (CRE; 5'-TCGAGCTCCTAGCCTGACGTCAGAGAGAGAGC-3') was performed as described above with the exception that the binding reactions were performed in the presence of $1 \mu \mathrm{g}$ of poly $(\mathrm{dI}-\mathrm{dC})$.

For experiments involving addition of antibodies to whole-cell extracts before gel shift analysis, $2 \mu$ l of either vehicle $[1 \mathrm{mg} / \mathrm{ml}$ bovine serum albumin (BSA) in PBS] or monoclonal antibodies raised against HSF1 or HSF2 (anti-HSF1 or anti-HSF2, respectively) was added to whole-cell extracts and incubated for $30 \mathrm{~min}$ at room temperature before incubation with the oligonucleotide probe. Anti-HSF1 and anti-HSF2 were prepared by J. J. Cotto (Morimoto Laboratory, Northwestern University, Evanston, IL) from hybridoma supernatant.

Gel shift analysis of partially purified mouse recombinant HSF1 and HSF2 (rHSF1 and rHSF2, respectively) was performed as described for glia and primary cultured hippocampal neurons (HIP). HSF1 (103 ig) and HSF2 (12.5 ng) were added to each lane.

\section{RESULTS}

Consistent with some in vivo reports (Sprang and Brown, 1987; McCabe and Simon, 1993), we found that heat shock was unable to induce the synthesis of HSP70 in HIP (Fig. 1). Primary hippocampal neurons (Fig. 14) were heat-shocked for $60 \mathrm{~min}$ at 10.2 or $42.5^{\circ} \mathrm{C}$ and allowed to recover at $37^{\circ} \mathrm{C}$ for $3,6,12$, or $24 \mathrm{hr}$. As can be seen, HSP70 induction was not observed at either of these temperatures (Fig. $1 B$ ) or at a number of temperatures between 37 and $42.5^{\circ} \mathrm{C}$ (data not shown). A heat shock of $42.5^{\circ} \mathrm{C}$ was selected because a $30-180 \mathrm{~min}$ exposure to this temperature has been shown to induce HSP synthesis in cultured cerebellar granule cells (Lowenstein et a1., 1991). Unlike cultured cerebellar granule neurons, exposure of HIP to $42.5^{\circ} \mathrm{C}$ heat shocks $>60 \mathrm{~min}$ in duration resulted in significant cell death (data not shown). As has been reported previously in vivo, the inducible form of HSP70 was not expressed constitutively (Kato et al., 1993) (Fig. 1B). To ensure the presence of protein, the blot was reprobed for HSP90 (Fig. 1C). As can be seen, all lanes demonstrated immunoreactivity to anti-HSP90. Constitutive expression of HSP90 has been reported previously in vivo (Gass et al., 1994) and was observed here in vitro. We also found that HIP neurons grown in contact with glial cells did not elicit a heat shock response as determined by immunocytochemistry (data not shown).

In contrast to the HIP, secondary cultured glial cells (GLIA; Fig. $1 D$ ) taken from the hippocampus and cortices of 3-5 d postnatal rat pups demonstrated a robust response after heat shock (Fig. $1 E$ ). Immunoreactivity to anti-HSP70 in GLIA was observed at $3 \mathrm{hr}$ aftcr a $60 \mathrm{~min} 42.5^{\circ} \mathrm{C}$ hcat shock and persisted for at least $24 \mathrm{hr}$. Immunoreactivity to anti-HSP70 was not observed after a $60 \mathrm{~min}$ heat shock at $40.2^{\circ} \mathrm{C}$. To ensure that protein was present, the blot was reprobed for HSP90 (Fig. $1 F$ ). It is unclear whether heat shock induced HSP90 synthesis in HIP and GLIA, because both cell types express high basal levels of this protein (Fig. $1 C, F$ ).

Manzerra and Brown (1992) have reported the inability of large motor neurons to induce hsp70 mRNA after hyperthermia in rabbits. They suggested that the cell type differences observed between neurons and glia in eliciting a heat shock response after hyperthermia can be explained by the levels of HSC70 (Manzerra and Brown, 1992). Neurons may express HSC70 to a higher level than glial cells and, as a result, may not need to induce HSP70 after heat shock (Manzerra and Brown, 1992). To rule out the possibility that elevated HSC70 expression in HIP results in down- 
A HIPPOCAMPAL NEURONS

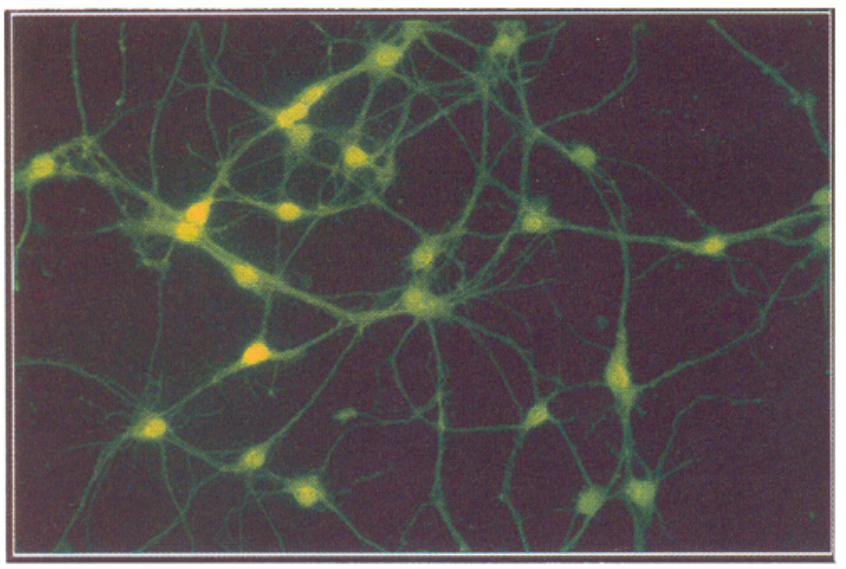

B $\stackrel{42.5^{\circ}}{\longrightarrow} \quad 40.2^{\circ}, 42.5^{\circ} \mathrm{C}$

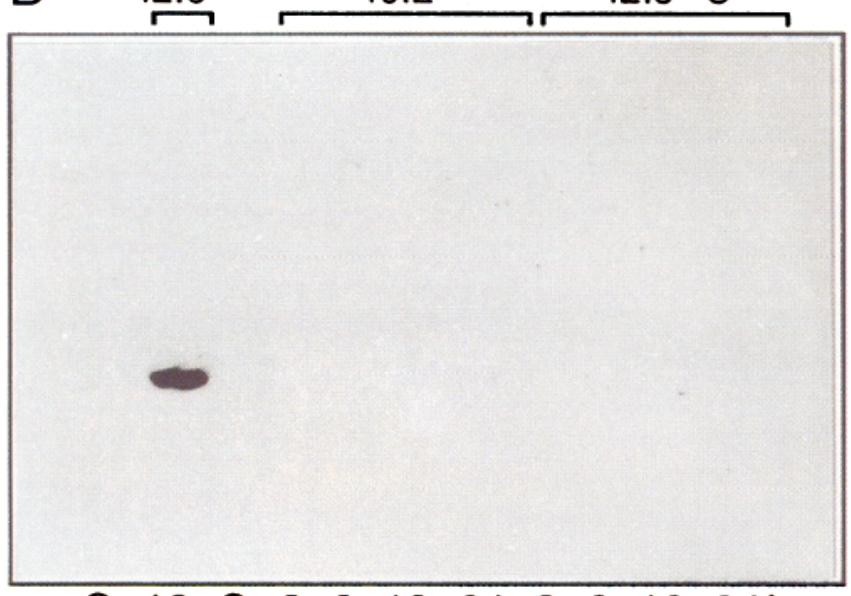

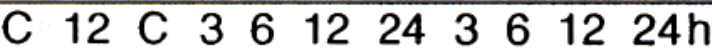

C
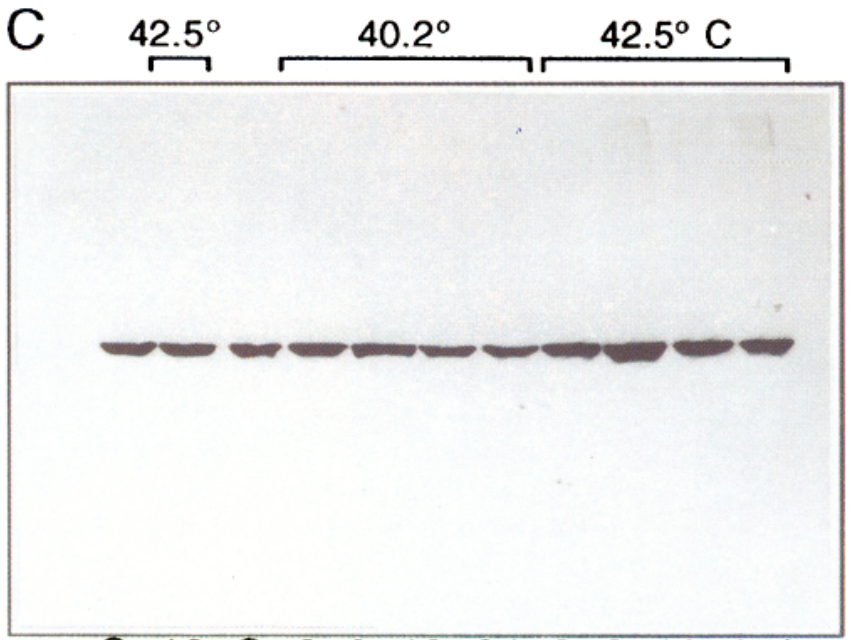

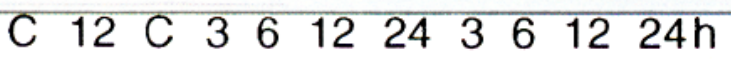

D GLIALCELLS

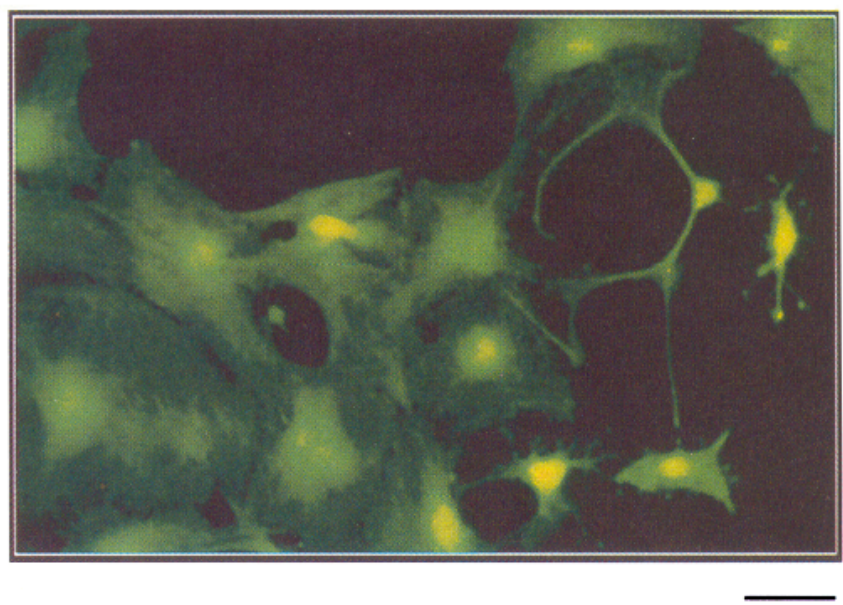

E

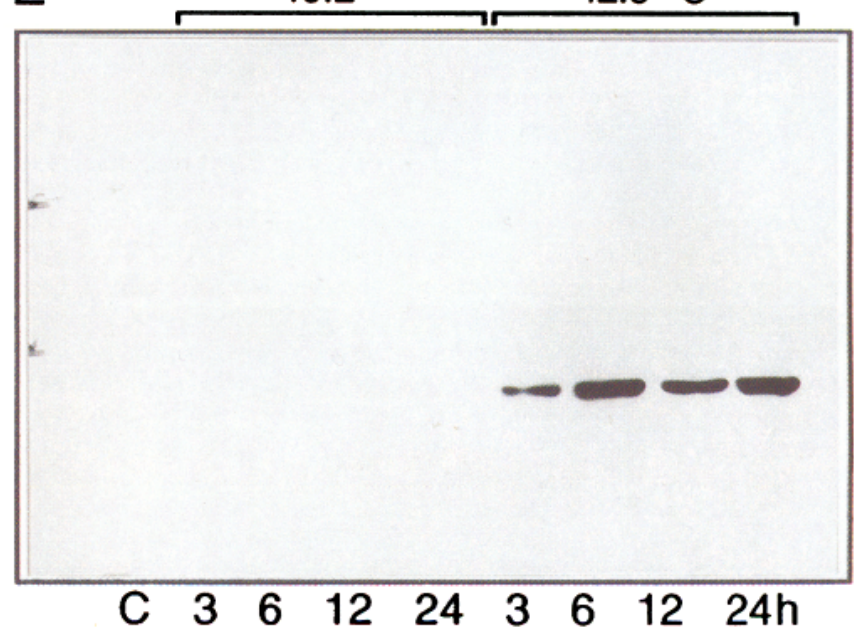

$\mathrm{F}$

$40.2^{\circ}$

$42.5^{\circ} \mathrm{C}$

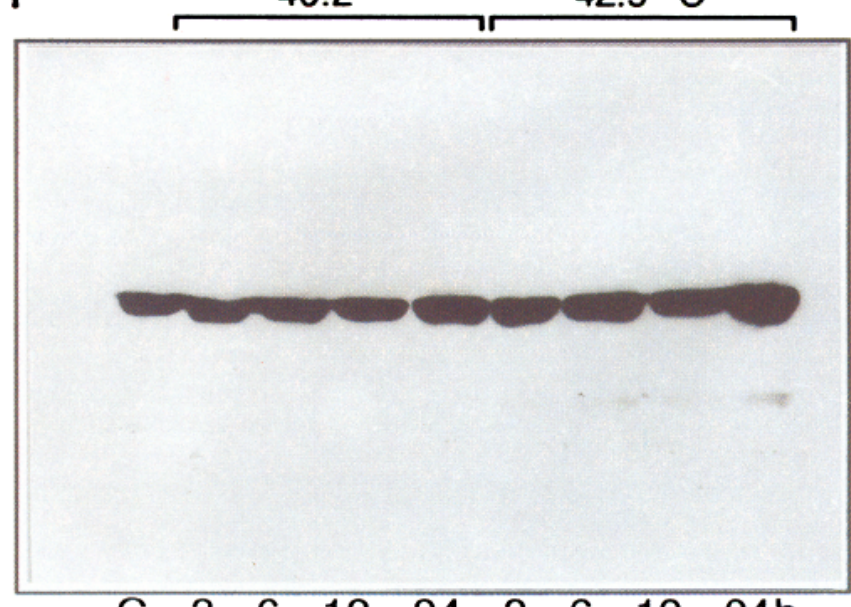




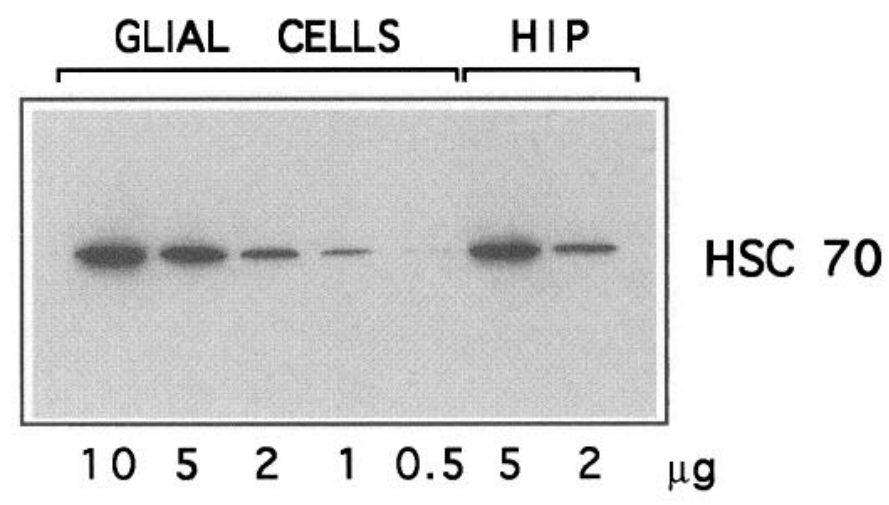

Figure 2. Comparison of HSC70 levels in HIP and GLIA. Unstressed GLIA and HIP extracts were examined by Western blot analysis using a monoclonal antibody specific for both the constitutive (HSC70) and inducible (HSP70) forms of the $70 \mathrm{kDa}$ heat shock protein family. Under unstressed conditions, HSP70 induction is not observed in either cell type. GLIA whole-cell extract at $10,5,2,1$, and $0.5 \mu \mathrm{g}$ was added to the first five lanes, whereas 5 and $2 \mu \mathrm{g}$ of HIP whole-cell extract was added to the last two lanes.

regulation of HSP70, we compared HSC70 levels in HIP and GLIA extracts. As shown in Figure 2, HIP express approximately equal amounts of HSC70 [80 $\pm 10 \%$ compared with GLIA (per $\mu \mathrm{g}$ of protein); $n=3$ ] as GLIA. These results suggest that elevated expression of HSC70 in HIP neurons is not responsible for the lack of HSP70 induction in HIP.

Taken together, these results demonstrate a significant difference in the ability of the two cell types taken from the brains of the same species to respond to a given stress. For heat shock genes to be expressed after heat shock, HSF1 first must be activated so that it binds to the HSE located in the promoters of the heat shock genes (Morimoto et al., 1992; Lis and Wu, 1993; Morimoto, 1993). To determine the molecular mechanism underlying the inability of HIP to induce HSP70, we examined the role of the HSF. Whole-cell extracts obtained from heat-shocked HIP and GLIA were examined for DNA-binding activity to an exogenous HSE. HSE-binding activity was observed in GLIA extracts heat-shocked for $60 \mathrm{~min}$ at 40.2 and $42.5^{\circ} \mathrm{C}$ (Fig. $3 A$ ). The intensity of the shifted band consistently was much greater after a $42.5^{\circ} \mathrm{C}$ heat shock than after a $40.2^{\circ} \mathrm{C}$ hyperthermic stress. This result corroborates the amount of HSP70 induction observed after the two heat shocks. A $42.5^{\circ} \mathrm{C}$ stress resulted in HSP70 induction, whereas a $40.2^{\circ} \mathrm{C}$ stress, at least at the protein level, did not result in such induction for the periods of recovery studied (Fig. $1 E$ ). The pattern of HSE-binding activity in HIP extracts was quite different from that of the GLIA extracts. Weak, but detectable, constitutive DNA-binding activity was observed in control cells, with further induction noted after a $40.2^{\circ} \mathrm{C}$ heat shock (Fig. $3 A$ ). After a $42.5^{\circ} \mathrm{C}$ heat shock, reduced HSE-binding activity was observed (Fig. $3 A$ ). As an additional positive control, extracts from FIII cells, a rat fibroblast cell line, incubated at $42^{\circ} \mathrm{C}$ for 60 min demonstrated HSE-binding activity that could be competed away with a 200 -fold excess of unlabeled oligonucleotide probe (Fig. $3 A$ ).

As a positive control for transcription factor binding in HIP, HIP extracts were incubated with an oligonucleotide probe containing the CRE. Figure $3 B$ demonstrates the multiple CREbinding complexes observed in HIP extracts under both stressed and control conditions. Specificity was confirmed using a 200 -fold excess of unlabeled CRE-containing probe (Fig. $3 B$ ).

Previously, it was demonstrated that HSF1 is the factor responsible for mediating heat-induced heat shock gene expression (Sarge et al., 1993). This factor exists as a monomer in unstressed mammalian cells. After heat shock, the factor forms a homotrimer that is then capable of binding to the HSE to initiate gene expression (Westwood et al., 1991; Baler et al., 1993; Westwood and $\mathrm{Wu}, 1993)$. After oligomerization, an inducible phosphorylation event occurs that may act to enhance the transcriptional properties of HSF1. A deficiency in any part of this process might result in a diminished heat shock response. Yet another possibility is the differential expression of one or more of the HSF.

As shown in Figure 4, the lack of a heat shock response in HIP exposed to hyperthermia may be attributable to deficient HSF1 expression. Western blot analysis of GLIA and HIP extracts with anti-HSF1 revealed immunoreactivity in GLIA under all three conditions with a much different pattern observed for HIP extracts (Fig. $4 A$ ). In contrast to GLIA, immunoreactivity to anti-HSF1 was not detected in HIP extracts with the exception of a faint band observed after a $42.5^{\circ} \mathrm{C}$ heat shock. Longer exposures were necessary to detect this band. This signal is contributed most likely by the $4 \%$ GLIA contamination of the neuronal cultures (see Materials and Methods). The low level of HSF1 immunoreactivity detected in extracts prepared from $42.5^{\circ} \mathrm{C}$ heat-shocked HIP may account for the upper portion of the slightly elevated shift in HSE-binding activity observed after a $42.5^{\circ} \mathrm{C}$ heat shock over that after a $40.2^{\circ} \mathrm{C}$ heat shock (Fig. $3 A$ ). The apparent increase in molecular weight of HSF1 bands has been shown previously to be caused by phosphorylation, because phosphatase pretreatment results in a lower molecular weight for HSF1 in extracts obtained from heat-shocked cells (Sarge et al., 1993). Interestingly, the extent of phosphorylation of HSF1 in glial cells was temperaturedependent (Fig. 4A). FIII cells also demonstrated immunoreactivity to anti-HSF1 (Fig. $4 A$ ). Our inability to detect HSF1 in HIP could have resulted from insufficient gene expression, untranslated message, or protein degradation. Yet another possibility is that the protein is expressed below the limit of detection. To exclude the possibility that HSF1 was degraded as a result of sample preparation, we added rHSF1 to neuronal extracts. Western blot analysis with anti-HSF1 did not reveal degradation of the exogenously added protein (data not shown).

Although HIP do not appear to express HSF1, they express HSF2 (Fig. $4 B$ ). The Western blot depicted in Figure $4 A$ was

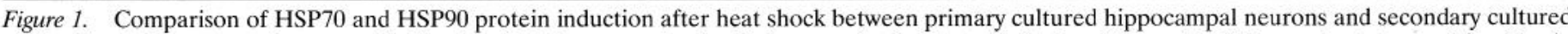

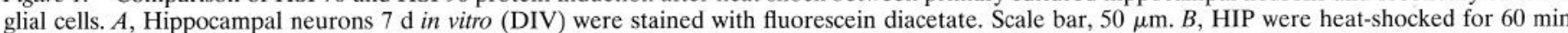

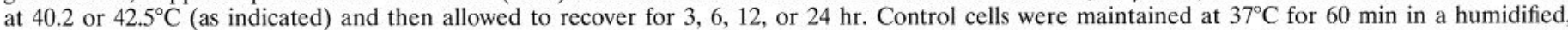

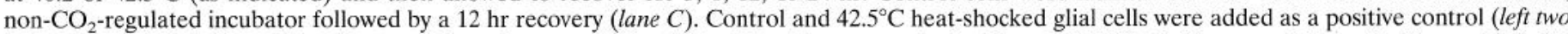

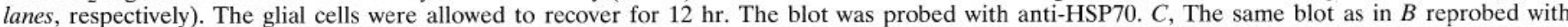

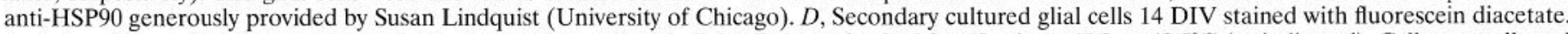

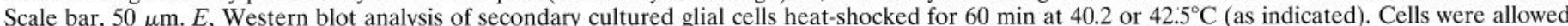

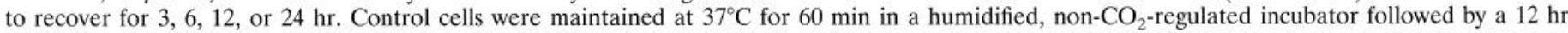
recovery $($ lane $C$ ). The blot was probed with anti-HSP70. $F$, The same blot as $E$ reprobed with anti-HSP90. 
A

Figure 3. HSE-binding activity of glial cell and hippocampal neuron extracts. $A$, GLIA and HIP were heat-shocked for $60 \mathrm{~min}$ at 40.2 or $42.5^{\circ} \mathrm{C}$ and analyzed with gel mobility shift analysis. Control cells are shown (Cont). As a positive control, FIII cells were unstressed (Cont) or heat-shocked for $60 \mathrm{~min}$ at $42^{\circ} \mathrm{C}$. Competition analysis with a 200-fold excess of unlabeled HSE oligonucleotide (Comp) confirmed specificity of DNA binding. $B$, Gel mobility shift analysis performed with a CRE-containing oligonucleotide probe. Neurons were heat-shocked for $60 \mathrm{~min}$ at 40.2 or $42.5^{\circ} \mathrm{C}$. Control HIP neurons are shown (Cont). Competition analysis with excess cold CRE was performed with extracts from $40.2^{\circ} \mathrm{C}$ heatshocked neurons (Comp). $F$ indicates free probe.

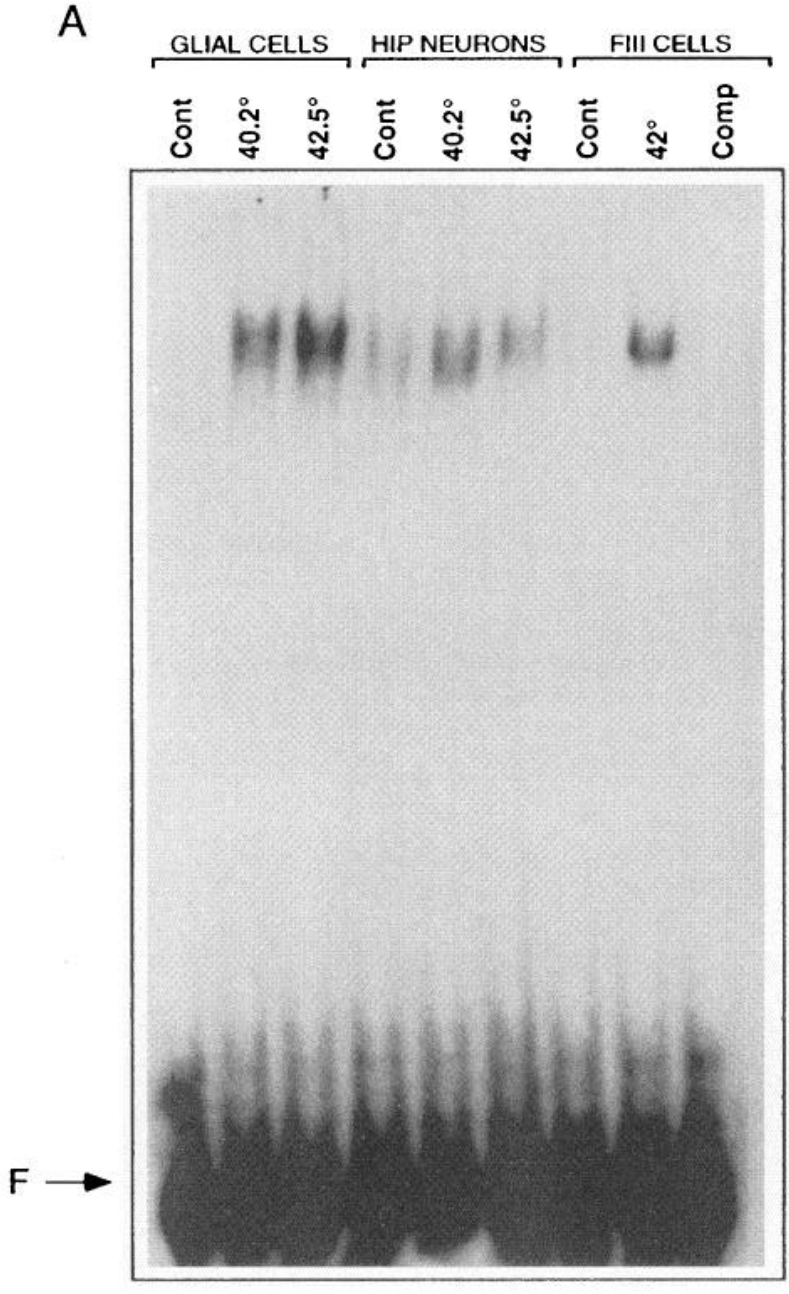

reprobed with anti-HSF2. As shown in Figure $4 B$, both GLIA and HIP expressed HSF2. The physiological role of HSF2 is unclear. However, activation of HSF 2 by hemin during differentiation of human K562 erythroleukemia cells suggests a role in cellular growth and differentiation (Sistonen et al., 1992, 1994).

The HSF responsible for the HSE-binding activities in the GLIA and HIP extracts was determined using anti-HSF1 and anti-HSF2. Consistent with the Western blot analysis, HSE-binding activity of GLIA was found to be attributable to HSF1 (Fig. $5 A$ ), whereas HSF 2 was responsible for the DNA-binding activity observed in HIP (Fig. $5 B$ ). Incubation of GLIA extracts with anti-HSF1 before incubation with radiolabeled oligonucleotide resulted in a supershifted band compared with extracts pretreated with BSA (Fig. 5A). Pretreatment with anti-HSF2 had no effect (Fig. $5 A$ ). In contrast, incubation of HIP extracts with anti-HSF2 resulted in a supershifted band in both control and heat-shocked cells, whereas incubation with anti-HSF1 resulted in a slightly shifted band (Fig. 5B). This pattern was observed with two different monoclonal antibodies raised against HSF1 (data not shown). Although we cannot rule out conclusively residual HSF1 DNA-binding activity contributed by the contaminating GLIA as causing the slightly shifted band, it is unlikely because the supershifted band is observed under control conditions. Since unstressed GLIA extracts do not demonstrate HSE-binding activity (Figs. $3 A, 5 A$ ), the slightly shifted band observed in HIP may result from either an inherent quality of the neurons, possibly another HSF, or cross-reactivity of anti-HSF1 for the trimeric form of HSF2. To examine the latter possibility, mouse rHSF1 and rHSF2, both constitutively capable of HSE binding, were examined with native gel shift analysis after incubation with anti-HSF1 and anti-HSF2, respectively (Fig. 6). As shown in Figure 6, cross-reactivity was not observed for either antibody. However, we cannot rule out cross-reactivity conclusively, because it is possible that the monoclonal antibodies prepared against mouse antigens cross-react with the rat forms of HSF1 and HSF2.

\section{DISCUSSION}

Our inability to detect HSP70 synthesis in primary cultured HIP after heat stress is in agreement with the in vivo results (Sprang and Brown, 1987; McCabe and Simon, 1993). In this study, we have demonstrated the differential expressiion of HSF1 and HSF2 in cultured HIP and GLIA. Although GLIA expressed both HSF1 and HSF2, HIP only expressed HSF2. The HIP lack HSF1, which has been shown to be the principal mediator of heat-induced heat shock gene expression (Sarge et al., 1993). After heat shock, glial HSF1 showed DNA-binding activity and, after transcription and translation, HSP70 was produced (Fig. 1). Western blot analysis demonstrated that HSP70 levels still were observed $24 \mathrm{hr}$ after a $42.5^{\circ} \mathrm{C}$ heat shock. In contrast to GLIA, the pattern of the HIP response to hyperthermia differed. HIP responded to heat shock by increasing HSF2 DNA-binding activity over that observed in control cells. However, despite the increased DNA-binding activity, HSF2 activation did not result in HSP70 induction in HIP. 


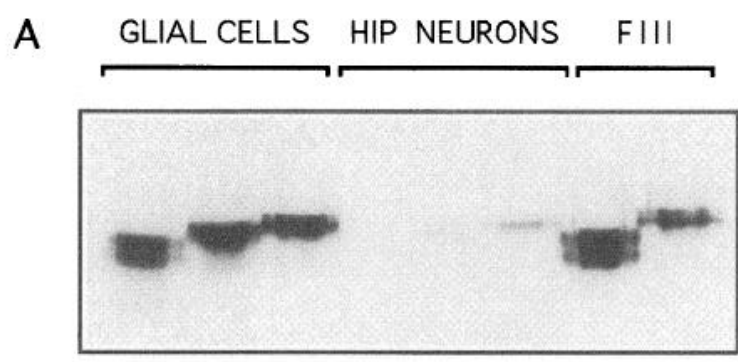

C $40.2^{\circ} 42.5^{\circ} \mathrm{C} 40.2^{\circ} 42.5^{\circ} \mathrm{C} \quad 42^{\circ}$
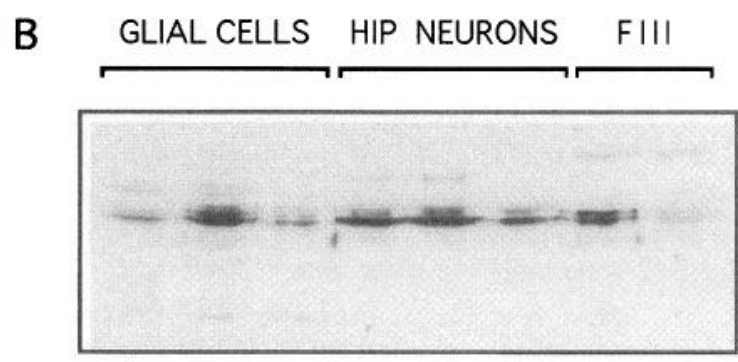

C $40.2^{\circ} 42.5^{\circ} \mathrm{C} 40.2^{\circ} 42.5^{\circ} \mathrm{C} 42^{\circ}$

Figure 4. HSF2, but not HSF1, is expressed in HIP. The same whole-cell extracts of heat-shocked and control GLIA and HIP ( $30 \mu \mathrm{g}$ of protein) used for the gel mobility shift analysis in Figure 3 were examined with Western blot analysis using polyclonal antisera raised against HSF1 $(A)$ and HSF2 (B). After examination with anti-HSF1, the blot was stripped and reprobed with anti-HSF2, confirming the presence of protein in the neuronal lanes. GLIA and HIP neurons were heat-shocked for $60 \mathrm{~min}$ at 40.2 or $42.5^{\circ} \mathrm{C}$. FIII cells were heat-shocked at $42^{\circ} \mathrm{C}$ for $60 \mathrm{~min}$. Control cells are shown in lanes labeled $C$.
Interestingly, HSF2 in GLIA was not activated because of the heat stress. HSF2 has been shown previously to be a modulator of heat shock gene expression under nonstress conditions such as cell differentiation (Sistonen et al., 1992, 1994) and spermatogenesis (Sarge et al., 1994). In light of the current results, it appears that HSF2 DNA-binding activity in neurons also can be activated during periods of environmental stress. It remains to be determined whether activation of HSF2 after environmental stress occurs only in the absence of other HSF, particularly HSF1. Nevertheless, the degree of HSF2 activation in HIP was not sufficient to drive the production of HSP70, which is consistent with the view that HSF2 is less able than HSF1 to direct this response (Sistonen et al., 1992, 1994). In addition, HSF DNAbinding activity does not correlate necessarily with hsp70 gene transcription, as was found in murine erythroleukemia cells (Hensold et al., 1990) and HeLa cells treated with sodium salicylate (Jurivich et al., 1992).

Although we did not observe HSP70 induction in hippocampal neurons, induction of HSP70 after hyperthermia has been demonstrated in cerebellar granule neurons (Lowenstein et al., 1991). HSP70 induction also has been observed in central neurons after kainic acid-induced status epilepticus (Vass et al., 1989), flurothyl-induced status epilepticus (Lowenstein et al., 1990), tissue injury (Brown et al., 1989), and ischemia (Vass et al., 1988; Sharp et al., 1991; Kato et al., 1993). The presence of HSP70 may play a major role in protecting the injured neuron from death. Several studies have demonstrated the involvement of the $70 \mathrm{kDa}$ members of the heat shock protein family in the protection of cells (Johnston and Kucey, 1988; Riabowol et al., 1988; Uney et al., 1993). Kirino et al. (1991) found that gerbils given a mild ischemic insult ranging from 1 to $4 \mathrm{~d}$ before a second, more severe ischemic insult demonstrated increased neuronal preservation in the CA1 region of the
A GLIAL CELLS

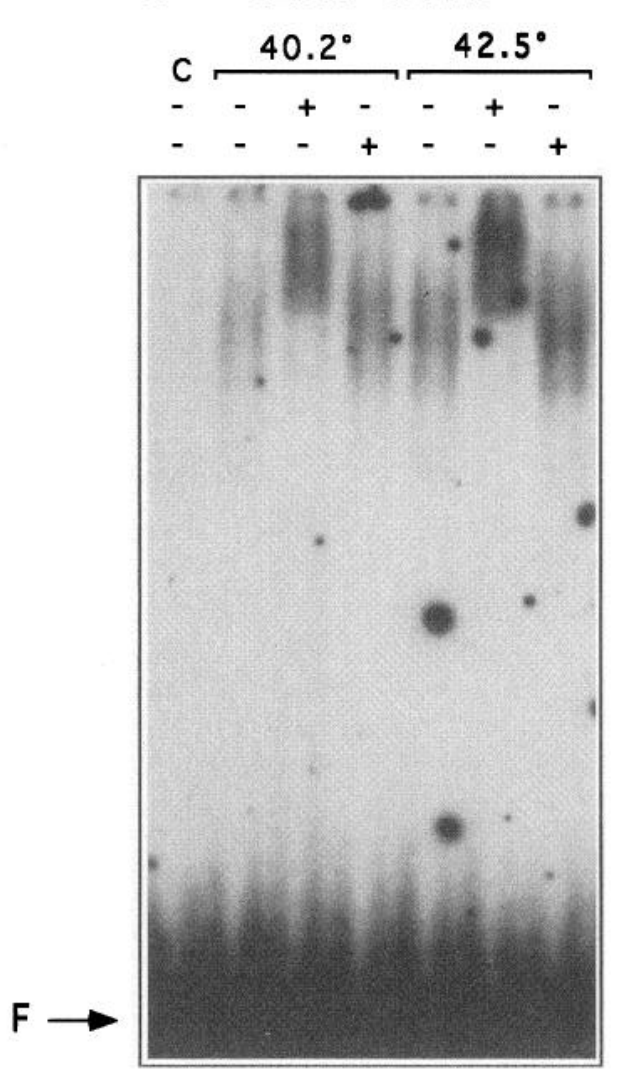

B HIP NEURONS

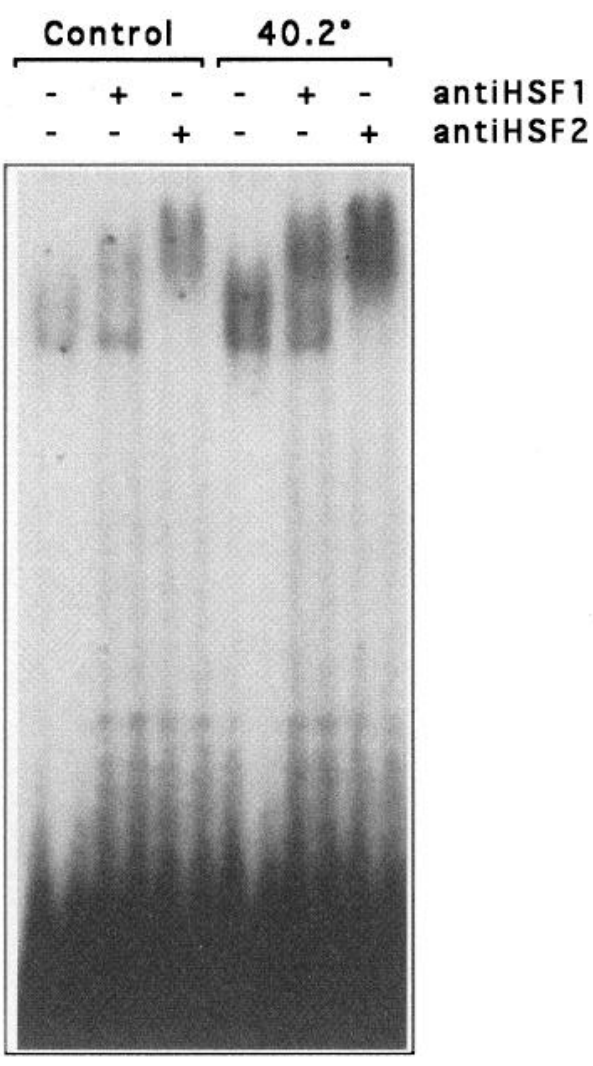

Figure 5. Comparison of HSE-binding activity of GLIA and HIP extracts after anti-HSF1 and anti-HSF 2 incubation. Gel mobility shift analysis was performed as described in Materials and Methods. Extracts were incubated for $30 \mathrm{~min}$ at $22^{\circ} \mathrm{C}$ with the vehicle, $1 \mathrm{mg} / \mathrm{ml} \mathrm{BSA}$ in PBS, or monoclonal antibodies raised against HSF1 or HSF2 (anti-HSF1, anti-HSF2, respectively) before incubation with the HSE oligonucleotide. $A$, GLIA were heat-shocked for $60 \mathrm{~min}$ at 40.2 and $42.5^{\circ} \mathrm{C}$. Control cells are shown in lane C. B, HIP neurons were heat-shocked for $60 \mathrm{~min}$ at $40.2^{\circ} \mathrm{C}$. Control cells are as indicated. $F$ indicates free probe. 
A

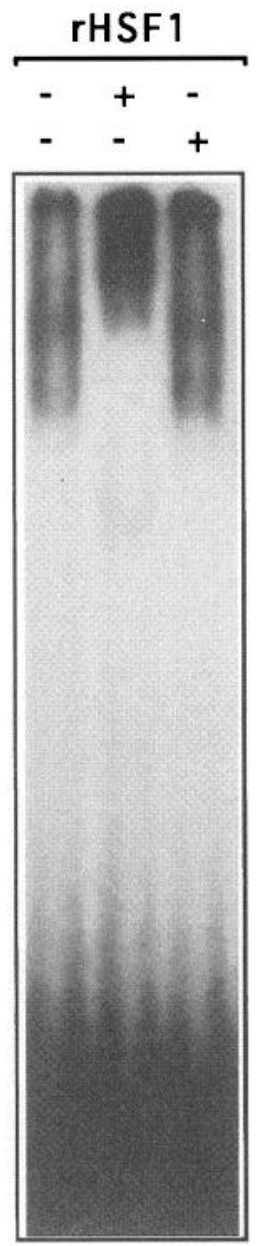

B

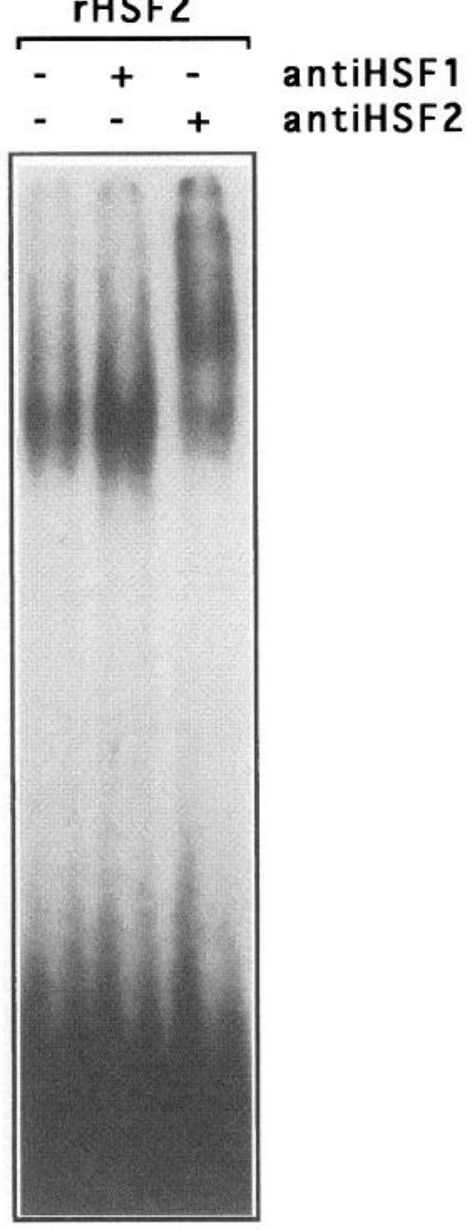

Figure 6. Comparison of HSE-binding activity of recombinant HSF1 (rHSF1) and HSF2 (rHSF2) after anti-HSF1 and anti-HSF2 incubation. Gel mobility shift analysis was performed as described in Figure 5. $A$, rHSF1 was added to each lane. $B$, rHSF2 was added to each lane.

hippocampus than gerbils that were not given mild ischemic pretreatments. Immunocytochemical analysis revealed immunoreactivity to antiHSP70 in CA1 pyramidal neurons (Kirino et al., 1991). These results highlight the importance of the stress response in the survival of a cell after trauma. Those cells possessing all of the components of the complete stress-protein system may be more resilient than those cells that express selective components. In this study, HIP were found to have similar levels of HSC70 as GLIA, suggesting that the deficient response of HIP to hyperthermia was not attributable to an overabundance of HSC70. Thus, with respect to HSP90 and HSC70, GLIA and HIP have the same arsenal of stress proteins under normal growth conditions. However, after heat shock, GLIA, which have the added benefit of HSF1, can induce HSP70 to protect the cell further from this stress.

Certain components of the stress-protein system may appear at different developmental stages for different cell types. As mentioned, the HIP used in this study were obtained from $17 \mathrm{~d}$ embryonic rat fetuses. Thus, the expression of HSF1 in this cell type could occur at a later developmental stage. Previous studies apparently have demonstrated some hsp70 mRNA induction in adult rat hippocampal pyramidal neurons after a $42^{\circ} \mathrm{C}$ heat shock (Pardue et al., 1992; David et al., 1994). However, compared with glial cells, hippocampal pyramidal neurons demonstrated a much weaker response to heat shock, which is consistent with the results of this study (see also Pardue et al., 1992). The induction of HSF2

HSE-binding activity observed in this study may account for the low level of hsp70 mRNA induction observed in the study by Pardue et al. (1992). Alternatively, expression of HSF1 at a later developmental stage may explain the induction of the hsp70 gene observed in adult rats (Pardue et al., 1992; David et al., 1994). Of interest, despite hsp70 mRNA induction the HSP70 protein is not detected immunocytochemically (McCabe and Simon, 1993). The developing CNS is particularly sensitive to hyperthermia (Edwards, 1981; Mirkes, 1985). Embryos exposed to elevated temperatures exhibit micrencephaly, anencephaly, and microphthalmia (Edwards, 1981; Mirkes, 1985). German (1984) hypothesized that the teratogenic effects of heat are caused by the heat-induced inhibition of transcription and translation of non-heat shock genes during a critical period in the development of the embryo. In addition, perhaps the lack of a complete stress-protein system in the embryonic nervous system results in the selective vulnerability of the embryo to hyperthermia.

To our knowledge, the observation of deficient HSF1 expression in HIP is the first example of its kind. These results suggest that, in addition to the regulatory mechanisms currently known for HSF (Morimoto et al., 1992; Lis and Wu, 1993; Morimoto, 1993), modulation by differential expression is yet another regulatory mechanism. It remains to be determined whether there is some overlap in the ability of different HSF to respond to the same stress. For example, the activation of HSF1 and HSF2 by oxidative injury may explain the HSP70 induction seen in hippocampal pyramidal neurons after ischemia even though these neurons appear not to express HSF1. Alternatively, ischemia may activate additional mechanisms that are necessary for HSP70 induction in this particular cell type. It is not clear whether it is the heat, or some manifestation of the heat (i.e., increased neurotransmitter release), that activates HSF2 in the HIP neurons. The fact that GLIA demonstrate HSF1 DNA-binding activity and not HSF2 DNA-binding activity after heat shock suggests that an indirect effect of heat results in activation of HSF2 in HIP. However, another possibility is that the activation of HSF2 is regulated differently in the absence of HSF1. Further experiments need to be performed to address this issue. In conclusion, we suggest that the neuron-specific regulation of the stress response as observed in this study represents a key element in the selective vulnerability of neurons to different types of insults, including those insults arising from trauma or stroke.

\section{REFERENCES}

Abele AE, Scholz KP, Scholz WK, Miller RJ (1990) Excitotoxicity induced by enhanced excitatory neurotransmission in cultured hippocampal pyramidal neurons. Neuron 2:413-419.

Akai F, Maeda M, Suzuki K, Inagaki S, Takagi H, Taniguchi N (1990) Immunocytochemical localization of manganese superoxide dismutase (Mn-SOD) in the hippocampus of the rat. Neurosci Lett 115:19-23.

Amici C, Sistonen L, Gabriella Santoro M, Morimoto RI (1992) Antiproliferative prostaglandins activate heat shock transcription factor. Proc Natl Acad Sci USA 89:6227-6231.

Baler R, Dahl G, Voellmy R (1993) Activation of human heat shock genes is accompanied by oligomerization, modification, and rapid translocation of heat shock transcription factor HSF1. Mol Cell Biol 13:2486-2496.

Bartlett WP, Banker GA (1984) An electron microscopic study of the development of axons and dendrites by hippocampal neurons in culture. I. Cells that develop without intercellular contacts. J Neurosci 4:1944-1953.

Booher J, Sensenbrenner M (1972) Growth and cultivation of dissociated neurons and glial cells from embryonic chick, rat and human brain in flask cultures. Neurobiology 2:97-105.

Bottenstein JE, Sato GH (1979) Growth of a rat neuroblastoma cell line in serum-free supplemented medium. Proc Natl Acad Sci USA 76:514-519. 
Brown IR, Rush S, Ivy GO (1989) Induction of a heat shock gene at the site of tissue injury in the rat brain. Neuron 2:1559-1564.

David J-C, Currie RW, Robertson HA (1994) Expression and distribution of hsp71 and hsc73 messenger RNAs in rat brain following heat shock: effect of dizocilpine maleate. Neuroscience 62:945-954.

Edwards MJ (1981) Clinical disorders of fetal brain development: defects due to hyperthermia. In: Fetal brain disorders-Recent approaches to the problem of mental deficiency (Hetzeland BS, Smith RM, eds), pp 335-364. Amsterdam: North-Holland.

Favaron M, Manev H, Alho H, Bertolino M, Ferret B, Guidotti A, Costa E (1988) Gangliosides prevent glutamate and kainate neurotoxicity in primary neuronal cultures of nennatal rat cerebellum and cortex. Proc. Natl Acad Sci USA 85:7351-7355.

Gass P, Schroder H, Prior P, Kiessling M (1994) Constitutive expression of heat shock protein 90 (HSP90) in neurons of the rat brain. Neurosci Lett 182:188-192.

German J (1984) Embryonic stress hypothesis of teratogenesis. Am J Med 76:293-301.

Hensold JO, Hunt CR, Calderwood SK, Housman DE, Kingston RE (1990) DNA binding of heat shock factor to the heat shock element is insufficient for transcriptional activation in murine erythroleukemia cells. Mol Cell Biol 10:1600-1608.

Johnston RN, Kucey BL (1988) Competitive inhibition of hsp70 gene expression causes thermosensitivity. Science 242:1551-1554.

Jurivich DA, Sistonen L, Kroes RA, Morimoto RI (1992) Effect of sodium salicylate on the human heat shock response. Science 255:1243-1245

Kato H, Liu X-H, Nakata N, Kogure K (1993) Immunohistochemical visualization of heat shock protein 70 in gerbil hippocampus following repeated brief cerebral ischemia. Brain Res 615:240-244.

Kirino T, Tsujita Y, Tamura A (1991) Induced tolerance to ischemia in gerbil hippocampal neurons. J Cereb Blood Flow Melab 11:299-307.

Kroeger PE, Sarge KD, Morimoto RI (1993) Mouse heat shock transcription factors 1 and 2 prefer a trimeric binding site but interact differently with the HSP70 heat shock element. Mol Cell Biol 13:3370-3383.

Li GC, Li L, Liu RY, Rehman M, Lee WMF (1992) Heat shock protein hsp70 protects cells from thermal stress even after deletion of its ATP-binding domain. Proc Natl Acad Sci USA 89:2036-2040.

Lindquist S, Craig EA (1988) The heat-shock proteins. Annu Rev Genet 22:631-677.

Lis J, Wu C (1993) Protein traffic on the heat shock promoter: parking, stalling, and trucking along. Cell 74:1 4 .

Liu X-H, Kato H, Nakata N, Kogure K, Kato K (1993) An immunohistochemical study of copper/zinc superoxide dismutase and manganese superoxide dismulase in ral hippocampus after transient cerebral ischemia. Brain Res 625:29-37.

Lowenstein DH, Chan PH, Miles MF (1991) The stress protein response in cultured neurons: characterization and evidence for a protective role in excitotoxicity. Neuron 7:1053-1060.

Lowenstein DH, Simon RP, Sharp FR (1990) The pattern of $72 \mathrm{kDa}$ heat shock protein-like immunoreactivity in the rat brain following flurothylinduced status epilepticus. Brain Res 531:173-182.

Manzerra P, Brown IR (1992) Expression of heat shock genes (hsp70) in rabbit spinal cord: localization of constitutive and hyperthermiainducible mRNA species. J Neurosci Res 31:606-615.

Marcuccilli CJ, Miller RJ (1991) CNS stress response: too hot to handle? Trends Neurosci 17:135-138.

Mattson MP, Rychlik B, Chu C, Christakos S (1991b) Evidence for calcium-reducing and excitoprotective roles for the calciunn binding protein calbindin-D28k in cultured hippocampal neurons. Neuron $6: 41-51$.

Mattson MP, Wang H, Michaelis EK (1991a) Developmental expression, compartmentalization, and possible role in excitotoxicity of a putative NMDA receptor protein in cultured hippocampal neurons. Brain Res 565:94-108.

McCabe T, Simon RP (1993) Hyperthermia induces $72 \mathrm{kDa}$ heat shock protein expression in rat brain in non-neuronal cells. Neurosci Lett 159:163-165.

Mirkes PE (1985) Effects of acute exposures to elevated temperatures on rat embryo growth and development in vitro. Teratology 32:259-266.

Mosser DD, Kotzbauer PT, Sarge KD, Morimoto RI (1990) In vitro activation of heat shock transcription factor DNA-binding by calcium and biochemical conditions that affect protein conformation. Proc Natl Acad Sci USA 87:3748-3752.

Mosser DD, Theodorakis NG, Morimoto RI (1988) Coordinate changes in heat shock element-binding activity and hsp70 gene transcription rates in human cells. Mol Cell Biol 8:4736-4744.

Morimoto RI (1993) Cells in stress: transcriptional activation of heat shock genes. Science 259:1409-1410.

Morimoto RI, Sarge KD, Abravaya K (1992) Transcriptional regulation of heat shock genes. J Biol Chem 267:21987-21990.

Nakai A, Morimoto RI (1993) Characterization of a novel chicken heat shock transcription factor, heat shock factor 3 , suggests a new regulatory pathway. Mol Cell Biol 13:1983 1997.

Nishimura RN, Dwyer BE, Welch W, Cole R, de Vellis J, Liotta K (1988) The induction of the major heat-stress protein in purified rat glial cells. J Neurosci Res 20:12-18.

Pardue S, Groshan K, Raese JD, Morrison-Bogorad M (1992) Hsp70 mRNA induction is reduced in neurons of aged rat hippocampus after thermal stress. Neurobiol Aging 13:661-672.

Rabindran SK, Giorgi G, Clos J, Wu C (1991) Molecular cloning and expression of a human heat shock factor, hsf1. Proc Natl Acad Sci USA 88:6906-6910.

Riabowol KT, Mizzen LA, Welch WJ (1988) Heat shock is lethal to fibroblasts microinjected with antibodies against hsp70. Science 242:433-436.

Sanchez Y, Taulien J, Borkovich KA, Lindquist S (1992) Hsp104 is required for tolerance 10 many forms of stress. EMBO J 11:2357-2364.

Sarge KD, Murphy SP, Morimoto RI (1993) Activation of heat shock gene transcription by heat shock factor 1 involves oligomerization, acquisition of DNA-binding activity, and nuclear localization and can occur in the absence of stress. Mol Cell Biol 13:1392-1407.

Sarge KD, Park-Sarge O-K, Kirby JD, Mayo KE, Morimoto RI (1994) Regulated expression of heat shock factor 2 in mouse testis: potential role as a regulator of $h s p$ gene expression during spermatogenesis. Biol Reprod 50:1334-1343.

Sarge KD, Zimarino V, Holm K, Wu C, Morimoto RI (1991) Cloning and characterization of two mouse heat shock factors with distinct inducible and constitutive DNA-binding ability. Genes Dev 5:1902-1911.

Scharf K-D, Rose S, Zott W, Schöff F, Nover L (1990) Three tomato genes code for heat stress transcription factors with a region of remarkable homology to the DNA-binding domain of the yeast hsf. EMBO J 9:4495-4501

Schuetz TJ, Gallo GJ, Sheldon L, Tempst P, Kingston RE (1991) Isolation of a cDNA for HSF2: evidence for two heat shock factor genes in humans. Proc Natl Acad Sci USA 88:6911-6915.

Sharp FR, Lowenstein D, Simon R, Hisanaga K (1991) Heat shock protein hsp 72 induction in cortical and striatal astrocytes and neurons following infarction. J Ccrcb Blood Flow Mctab 11:621-627.

Sistonen L, Sarge KD, Morimoto RI (1994) Human heat shock factors 1 and 2 are differentially activated and can synergistically induce hsp70 gene transcription. Mol Cell Biol 14:2087-2099.

Sistonen L, Sarge KD, Phillips B, Abravaya K, Morimoto RI (1992) Activation of heat shock factor 2 during hemin-induced differentiation of human erythroleukemia cells. Mol Cell Biol 12:4104-4111.

Sprang GK, Brown IR (1987) Selective induction of a heat shock gene in fibre tracts and cerebellar neurons of the rabbit brain detected by in situ hybridization. Mol Brain Res 3:89-93.

Uney JB, Kew JNC, Staley K, Tyers P, Sofroniew MV (1993) Transfection mediated expression of human Hsp70i protects rat dorsal root ganglion neurons and glia from severe heat stress. FEBS Lett 334:313-316

Vass K, Berger ML, Nowak Jr TS, Welch WJ, Lassmann H (1989) Induction of stress protein HSP70 in nerve cells after status epilepticus in the rat. Neurosci Lett 100:259-264.

Vass K, Welch WJ, Nowak Jr TS (1988) Localization of $70 \mathrm{kDa}$ stress protein induction in gerbil brain after ischemia. Acta Neuropathol $77: 128-135$.

Westwood JT, Wu C (1993) Activation of Drosophila heat shock factor: conformational change associated with a monomer-to-trimer transition. Mol Cell Biol 13:3481-3486.

Westwood JT, Clos J, Wu C (1991) Stress-induced oligomerization and chromosomal relocalization of heat-shock factor. Nature 353:822-827. 